\title{
SOCIOLOGIA PERIFÉRICA E QUESTAO RACIAL: revisitando Guerreiro Ramos
}

\section{INTRODUÇÃO}

\author{
Breno Bringel \\ Christian Edward Cyril Lynch ${ }^{* *}$ \\ Marcos Chor Maio
}

Política, pensamento político-social, sociologia periférica e questão racial são temas relevantes na obra do sociólogo baiano Alberto Guerreiro Ramos (1915-1982). Cientista social que esteve no centro do debate intelectual nos anos 1950 e 1960, Guerreiro foi um pensador de grande influência nas contendas sobre o padrão mais pertinente do trabalho sociológico em países periféricos. Participou, ainda, na discussão das relações entre ensaísmo e ciências sociais; na identificação, pela primeira vez, das "famílias" do pensamento político-social brasileiro; na análise da intelligentsia; nas abordagens sobre uma sociologia de intervenção e/ou de caráter aplicado; na delimitação da teoria e da prática da administração pública no Brasil; nas controvérsias em torno das relações

\footnotetext{
* Doutor em Ciência Política e Sociologia. Professor-pesquisador do IESP-UERJ. Bolsista de Produtividade do CNPq e Jovem Cientista do Nosso Estado - FAPERJ.

Rua da Matriz, 82. Cep: 22260100. Botafogo - Rio de Janeiro - Rio de Janeiro - Brasil. brenobringel@iesp.uerj.br

${ }^{* \star}$ Doutor em Ciência Política. Professor do Instituto de Estudos Sociais e Políticos da Universidade do Estado do Rio de Janeiro (IESP-UERJ) e pesquisador da Fundação Casa de Rui Barbosa (FCRB).

Rua da Matriz 82. Botafogo. Cep: 22260100. Rio de Janeiro, Rio de Janeiro - Brasil. clynch3@hotmail.com

**** Doutor em Ciência Política. Professor do Programa de Pós-graduação em História das Ciências e da Saúde da Casa de Oswaldo Cruz, PPGHCS/COC/Fiocruz. Pesquisador $\mathrm{CNPq} 1 \mathrm{~B}$

Av. Brasil 4036, sala 403. Manguinhos. Cep: 21040361. Rio de Janeiro - Rio de Janeiro - Brasil. maio@fiocruz.br
}

entre desenvolvimento econômico e político; nos esforços de formulação de uma teoria da sociedade brasileira; nas análises dos significados da dimensão psicossocial do "problema do negro", do racismo, da democracia racial e da subjetividade negra, sempre em diálogo com a negritude francófona.

Estes são alguns dos tópicos enfrentados originalmente por Guerreiro Ramos que, a despeito do crescente interesse acadêmico no autor, ${ }^{1}$ ainda são pouco explorados pelos estudiosos da intelectualidade brasileira. Em parte, o "esquecimento" da obra de Guerreiro Ramos deve-se ao período do regime militar, quando o Instituto Superior de Estudos Brasileiros - ISEB - instituição criada, dentre outros, pelo sociólogo, veio a ser concebido por seus adversários acadêmicos como uma "fábrica de ideologias" (Toledo, 1977), uma poderosa categoria de acusação que levou o ISEB e sua rica produção intelectual a uma condição marginal.

Personagem polêmico e sociólogo inquieto, pode-se localizar quiçá também em seu próprio estilo e trajetória parte do olvido.

${ }^{1}$ Entre os autores que têm publicado artigos recentes em periódicos brasileiros, resgatando aspectos cruciais da obra de Guerreiro Ramos, destacam-se, Ariston Azevedo, Edison Bariani, Fernando Filgueiras, João Marcelo Maia e Marcos Chor Maio. 
Teórico da esquerda democrática trabalhista, defensor do desenvolvimentismo e da autodeterminação nacional, cultor da polêmica intelectual, crítico simultâneo do marxismo e do neoliberalismo, ele vivia, como poucos, o alucinante ritmo da vida política experimentada a partir da segunda eleição de Vargas para a presidência da República. Intelectual brilhante, o sociólogo baiano foi guiado por uma grande ambição intelectual e política. Servidor da burocracia federal, Guerreiro elaborara, em 1953, o projeto de uma ciência social brasileira, pós-colonial, politicamente orientada. Naquela posição, veio a bater de frente com a sociologia paulista de Florestan Fernandes, que começava a organizar a disciplina do ponto de vista institucional e com ele polemizar nos anos seguintes. Aderiu, em seguida, ao projeto nacional-desenvolvimentista encabeçado por Hélio Jaguaribe no IBESP e, depois, no ISEB, de cujo departamento de sociologia tornou-se chefe. Entretanto, a "aceleração histórica que hoje marca a nossa vida política” (Ramos, 1963, p. 15) lhe impôs um ritmo crescente de intervenção no espaço público e de radicalização política de seu projeto intelectual.

Tornado um dos mais celebrados intelectuais brasileiros, Guerreiro saiu do ISEB em 1958 e passou a investir na política, com o propósito confesso de se tornar o principal ถ teórico do trabalhismo e, como tal, de orientar خิ ideologicamente o processo de transformação em curso, com base em sua teoria da sociedade สี brasileira. Em 1963, assumiu o cargo de depus tado federal pelo Partido Trabalhista Brasileiro के - PTB - com ânimo resoluto de ali permaneल cer como doutrinário do trabalhismo. Naque\& la condição, continuou a polemizar, atacando ๙ a abertamente tanto o liberalismo conservador

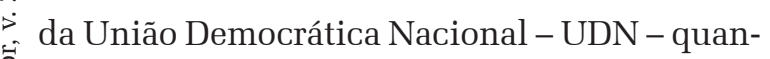
to o marxismo leninista do Partido Comunista (PCB). Em dez anos, portanto, o sociólogo burocrata, brandindo um nacionalismo tributário do Estado Novo, tornara-se deputado federal, disputando com San Tiago Dantas o papel de teórico do partido, então no poder com João
Goulart. Para quem desejara elaborar uma ideologia política que encaminhasse a revolução nacional com fundamento em uma teoria da sociedade brasileira, e que se via como o intelectual militante das classes sociais emergentes, a ação política direta e institucional era um caminho natural. Guerreiro não se deixava abater pelo preconceito racial presente no meio político: "Eu queria ser o nacional, nada menos que o máximo" (Oliveira, 1995, p. 175).

Essa aceleração do tempo histórico por ele reconhecida, que alçou o ambicioso Guerreiro tão rapidamente ao cume da cena política e intelectual brasileira, foi, porém, diretamente proporcional ao impacto devastador do golpe de 1964 para a sua carreira. Seu projeto político esfarelou-se e ele teve seu mandato de deputado cassado. Seus livros, em especial o último, Mito e Verdade da Revolução Brasileira, foram recolhidos pela censura. Embora tenha se refugiado no curso de administração da Fundação Getúlio Vargas, graças à proteção de Simão Lopes, Guerreiro perdeu qualquer possibilidade de inserção acadêmica na sociologia brasileira.

A intelectualidade progressista passou a se identificar quase toda com o marxismo que ele havia duramente atacado nos anos anteriores, fosse o marxismo leninista do PCB, fosse o marxismo acadêmico da USP. A radicalização da cena política e intelectual que se seguiu ao golpe, opondo a direita nacionalista à esquerda comunista, inviabilizou o lugar intelectual por ele ocupado: o de um intelectual nacionalista de esquerda, que não era marxista. O marxismo acadêmico, por sua vez, fez o processo do projeto desenvolvimentista da esquerda democrática a que Guerreiro estivera associado, criticando-o como um populista ideológico e conservador. A saída que Guerreiro encontrou foi a de seguir uma carreira - muito bem-sucedida, aliás - nas universidades americanas. Durante quinze anos esteve ausente da cena intelectual brasileira. Quando, afinal, ensaiava retornar a ela, ao tempo da abertura, morreu quase de repente, devido a um câncer fulminante. 
A leitura dos anais do seminário organizado pela FGV em sua homenagem, em 1983, deixa entrever o modo por que a maior parte da ciência social da época parecia vê-lo então: um intelectual brilhante e polêmico, que desafiara o establishment da academia com um ambicioso (e algo excêntrico) projeto intelectual nacionalista, que descambou pela política e perdeu o bonde da sociologia brasileira. Por isso mesmo, Guerreiro Ramos acabou "esquecido, marginalizado, excluído do panteão dos cientistas sociais brasileiros” (Oliveira, 1995, p. 9).

Contudo, desde pelo menos 1995, a obra sociopolítica de Guerreiro Ramos tem passado por uma reabilitação lenta, mas segura. Naquele ano, Wanderley Guilherme dos Santos e Clóvis Brigagão se encarregaram de republicar a Introdução Crítica à Sociologia Brasileira e a Redução Sociológica, ao passo que Lúcia Lippi Oliveira publicou a primeira tentativa de oferecer ao público um panorama geral, ainda que sintético, de sua obra: A Sociologia do Guerreiro. Na década seguinte, foram produzidas pelo menos três teses de doutorado, no âmbito das ciências sociais, que versavam diretamente sobre sua obra: Nacionalismo e democracia no Pensamento de Guerreiro Ramos, de Aparecida Maria Abranches (antigo IUPERJ, atual IESP-UERJ, 2006); A sociologia antropocêntrica de Guerreiro Ramos, de Ariston Azevedo (UFSC, 2006), e Guerreiro Ramos e a Redenção Sociológica: capitalismo e sociologia no Brasil, de Edison Bariani (UNESP, 2008), além de várias outras teses que buscaram releituras das polêmicas do autor dentro de debates e questões mais gerais das ciências sociais, como é o caso de Tatiana Gomes Martins em sua tese Florestan Fernandes e Guerreiro Ramos: para além de um debate (Unicamp, 2008). Ademais, nos últimos dez anos, o interesse pela obra de Guerreiro parece ter aumentado sobremaneira, tendo sido publicados a seu respeito alguns livros e pelo menos trinta artigos em diversos periódicos.

Como forma de contribuir com este movimento intelectual de retomada dos aportes de Guerreiro Ramos, alguns deles cada vez mais sugestivos, para o debate intelectual contemporâneo, celebrou-se, em novembro de 2012, no Instituto de Estudos Sociais e Políticos da Universidade do Estado do Rio de Janeiro (IESP-UERJ), o Seminário "Trinta Anos Sem Guerreiro Ramos". ${ }^{2}$ A ideia do presente dossiê origina-se neste encontro de 30 anos do falecimento de Guerreiro e, curiosamente, é publicado pelo Caderno CRH em 2015, quando se cumprem 100 anos de seu nascimento em Santo Amaro da Purificação. Simbolismos à parte, este dossiê pretende contribuir para revisitar alguns elementos fundamentais da vasta obra de Guerreiro Ramos, com o objetivo de cotejar suas contribuições com debates cruciais na contemporaneidade. Busca-se, em particular, fornecer novos olhares para dois eixos candentes que o sociólogo abordou com extrema acuidade: a sociologia periférica e as relações raciais.

\section{RELENDO GUERREIRO RAMOS: so- ciologia periférica e questão racial}

Além desta introdução, o presente dossiê compóe-se de sete artigos que tratam, a partir de olhares diversos, questões fundamentais associadas aos dois eixos supramencionados. Um dos pontos de partida fundamentais para a releitura de Guerreiro Ramos tem sido a recuperação e a atualização de um de seus livros mais emblemáticos, A Redução Sociológica. Na visão de Guerreiro, esta se afirmaria como obra "autêntica", na medida em que buscaria, no conhecimento sociológico clássico, instrumentos para a inteligibilidade de uma realidade local, culturalmente específica, reflexiva, embasada em experiência societária original. A obra é um indicador da importância do debate sobre o desenvolvimento e dos esforços de reflexão autóctone sobre a sociedade brasileira. Deve ser

${ }^{2}$ O Seminário contou com a participação de Breno Bringel, Carlos Antonio Costa Ribeiro, Cesar Guimarães, Christian Lynch, João Feres Júnior, João Marcelo Maia, Lúcia Lippi, Marcos Chor Maio, Norma Côrtes e Wanderley Guilherme dos Santos. 
lida em seu contexto de criação (artigo inicial de E. Bariani), mas, também, é passível de novas apropriações, como, de fato, o fazem vários dos autores deste dossiê, em função das questões seminais que abrem para a reconstrução da sociologia crítica na contemporaneidade.

Neste sentido, alguma das releituras do pensamento de Guerreiro Ramos em curso incluem o autor nos marcos da teoria pós-colonial. Isso pode ser feito através de vários caminhos. Uma primeira possibilidade é olhar para o período das lutas anticoloniais na África e do desenvolvimentismo brasileiro e latino-americano, buscando reconstruir, de forma minuciosa, nexos, reflexões e esforços de apreciação em conjunto de uma série de estudos concebidos, geralmente, de forma desconectada. Privilegiando trabalhos realizados no âmbito do IBESP e do ISEB, na década de 1950, esta tentativa de reconstituição e totalização de livros e artigos procura evidenciar a intensa interlocução de Guerreiro Ramos com o pensamento social brasileiro e, de modo mais geral, com a teoria social (C. Lynch, neste dossiê).

Por outro lado, a renovação dos denominados estudos pós-coloniais contemporâneos também tem instigado a releitura de autores fundamentais da periferia mundial dos anos 1950 e 1960. Neste sentido, a obra de Guerreiro Ramos pode ser interpretada como um capítuL lo da história da sociologia periférica no pós- $2^{\mathrm{a}}$ ธิ Guerra Mundial na interseção com a história global. Parcela significativa de sua produção สี intelectual dos anos 1950 associa projetos de m desenvolvimento, pensamento autônomo, vaके lorização da produção sociológica do Sul, da ^ perspectiva anticolonial e da crítica radical ao $\therefore$ eurocentrismo. Assim, os estudos de Guerrei-

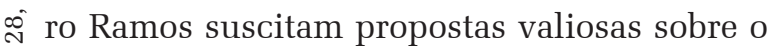

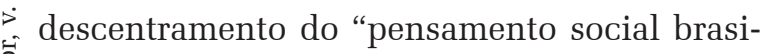
leiro" e sobre uma visão ampliada da história da sociologia (J. M. Maia, neste dossiê).

Haveria, no entanto, que indagar sobre que autores são recuperados e quais mantêmse no esquecimento, bem como de que maneira eles são recuperados e, eventualmente (re)ca- nonizados (algo tão caro à própria trajetória de Guerreiro), dentro de um debate pós-colonial contemporâneo que, muitas vezes, não dialoga com o contexto e com as premissas políticas, teóricas e epistemológicas do ambiente intelectual dos quais provêm. Neste sentido, até que ponto a crítica pós-colonial contemporânea (seja ela a escola subalterna asiática, o pensamento descolonial latino-americano ou aquelas correntes mais culturalistas existentes no centro do pensamento sociológico) consegue ir além da "denúncia epistemológica” para fornecer elementos de reconstrução da teoria social? Como Guerreiro Ramos pode contribuir nesta direção? (cf. o texto de B. Bringel e J.M. Domingues).

Se os quatro primeiros artigos do dossiê discutem, principalmente, a temática da sociologia periférica e a teoria pós-colonial, os últimos três textos buscam trazer novos elementos para a discussão das relações raciais e do "problema do negro", questão que atrai crescente interesse pelos escritos de Guerreiro Ramos e envolve uma ampla gama de temas: sua crítica à tradição de estudos afro-brasileiros; a influência de perspectivas sociológicas, a exemplo da Escola Sociológica de Chicago, sobre as relações entre raça e classe; as relações entre ciências sociais e engajamento político, inclusive as disputas disciplinares (sociologia versus antropologia) quanto ao tema da mudança social; o papel político do movimento negro brasileiro no processo de definição de agendas de combate ao racismo no plano internacional; o debate político em torno da negritude, em perspectiva transnacional; os contornos da ideologia da democracia racial à brasileira; e as contraditórias estratégias antirracistas de Guerreiro Ramos (os artigos de M. C. Maio e de L. A. Campos neste dossiê).

Além destes temas, torna-se importante avaliar as continuidades e descontinuidades do pensamento de Guerreiro, particularmente no momento da virada dos anos 1940 para os 1950, quando ocorre uma inflexão nas ideias de Guerreiro Ramos sobre a negritude, o pensamento social brasileiro e a sociologia brasileira. Acrescente-se o aspecto central do novo momento de 
Guerreiro, ou seja, sua fervorosa crítica à ideologia da brancura, que contemplaria, a um só tempo, intelectualidade e elites políticas. A teoria da branquidade aparece, assim, como questão central por sua tentativa de voltar à análise, não para o "problema do negro", e sim, para a constituição do branco em um sistema de relações raciais, o que nos leva a uma agenda de pesquisa mais abrangente - impulsionada no Brasil por nomes como Carlos Hasenbalg, Nelson do Valle e Silva e Antônio Sérgio Guimarães - sobre as desigualdades raciais. Contudo, a crítica da branquidade não se entende sem a afirmação da negritude e, por isso, o dossiê se encerra abrindo-se a um olhar comparativo e ampliado do "Atlântico Negro” ( $c f$. J. Feres Júnior), relacionando, assim, seus dois temas centrais: a sociologia periférica e a questão racial.

Recebido para publicação em 15 de novembro de 2014 Aceito em 11 de dezembro de 2014

\section{REFERÊNCIAS}

BARIANI, E. Guerreiro Ramos e a redenção sociológica: capitalismo e sociologia no Brasil. São Paulo: UNESP, 2011.

RAMOS, A.G. Mito e verdade da revolução brasileira. Rio de Janeiro, Zahar Editores, 1963.

OLIVEIRA, L. L. A Sociologia de Guerreiro. Rio de Janeiro: Editora UFRJ, 1995.

TOLEDO, C. N. ISEB: fábrica de ideologias. São Paulo: Ática, 1977.

Breno Bringel - Doutor pela Faculdade de Ciência Política e Sociologia da Universidade Complutense de Madri, onde foi professor. Professor Adjunto do Instituto de Estudos Sociais e Políticos (IESP) da Universidade do Estado do Rio de Janeiro (UERJ) e Coordenador, juntamente com José Mauricio Domingues, do Núcleo de Estudos de Teoria Social e América Latina (NETSAL). Editor de DADOS - Revista de Ciências Sociais e de openMovements, novo projeto de openDemocracy (www.opendemocracy.net/ openmovements). Bolsista PROCIÊNCIA (UERJ), Jovem Cientista do Nosso Estado (FAPERJ) e bolsista de Produtividade em Pesquisa do CNPq. Publicações recentes: Global modernity and social contestation, editado com José Maurício Domingues. Sage, 2015; O MST e o internacionalismo contemporâneo (Eduerj, no prelo); Les mobilisations de 2013 au Brésil: vers une reconfiguration de la contestation. Bresil(s), v. 7, p. 7-18, 2015

Christian Edward Cyril Lynch - Doutor em Ciência Política. Professor do Instituto de Estudos Políticos e Sociais da Universidade do Estado do Rio de Janeiro (IESP-UERJ - antigo IUPERJ). Pesquisador da Fundação Casa de Rui Barbosa do Ministério da Cultura (FCRB). Pesquisador nível 2 do CNPq e bolsista jovem cientista do nosso Estado da FAPERJ. Coordenador do grupo de trabalho de Teoria Política e Pensamento Político Brasileiro da Associação Nacional de Pós-Graduação em Ciências Sociais (ANPOCS). Coordenador da área temática de Pensamento Político Brasileiro da Associação Brasileira de Ciência Política (ABCP). Membro da diretoria do Instituto Brasileiro de História do Direito (IBHD). Atualmente coordenador do programa de pós-graduação em ciência política do IESP-UERJ e editor da Revista Insight Inteligência. Publicações recentes: Brésil de la Monarchie à l Oligarchie: construction de 1 État, institutions et représentation politique (1822-1930) (L Harmattan, 2011 - prefácio de Pierre Rosanvallon); Monarquia sem despotismo e liberdade sem anarquia: o pensamento político do Marquês de Caravelas (UFMG, 2014 - prefácio de Antônio Manuel Hespanha); Da Monarquia à Oligarquia: história institucional e pensamento político brasleiro (1822-1930) (Alameda, 2014).

Marcos Chor Maio - Doutor em Ciência Política. Professor do Programa de Pós-graduação em História das Ciências e da Saúde da Casa de Oswaldo Cruz, PPGHCS/COC/Fiocruz. Pesquisador da Casa de Oswaldo Cruz/Fundação Oswaldo Cruz. Bolsista de Produtividade em Pesquisa do CNPq 1B. Suas áreas de pesquisa e ensino são: História das Ciências Sociais no Brasil; Raça, Ciência e Saúde no Pensamento Social Brasileiro; Organizações Internacionais e Políticas Nacionais. Atualmente desenvolve pesquisas que versam sobre ciências sociais, estudos de comunidade e saúde no Brasil; interfaces entre sociologia, antropologia e psicologia social nos estudos sobre raça e racismo no Brasil; políticas sociais com recorte racial no campo da saúde pública no Brasil. Publicações recentes: Health at the dawn of development: the thought of Abraham Horwitz. História, Ciências, Saúde-Manguinhos (Impresso), v. 22, p. 69-93, 2015; Donald Pierson e o Projeto do Vale do Rio São Francisco: cientistas sociais em ação na era do desenvolvimento. Dados, v. 56, n. 2, p. 245-284, 2013. 
